\title{
Application of GFRP Bar in High - Rise Building Exterior Spraying Robot Zujia Zheng ${ }^{1,}{ }^{2}$, Xue Yang ${ }^{1}$, Kui Yang ${ }^{1}$ and Chong $\operatorname{Tan}^{2, a^{*}}$ \\ ${ }^{1}$ Infrastructure and Logistics Management, Wuhan University of Science and Technology, Wuhan 430065, China \\ ${ }^{2}$ Key Laboratory of Metallurgical Equipment and Control Technology, Ministry of Education, Wuhan University of Science and Technology, Wuhan 430081, China atc18983100080@163.com
}

Keywords: GFRP bar; Steel wire; Tensile test; High-rise building; Spraying robot

\begin{abstract}
The construction industry is a long-established industry. For a long time, building materials are usually used in traditional brick, stone, steel, concrete and other traditional building materials. At present, the exterior walls of major domestic buildings have been prohibited from being decorated with easily detachable materials such as ceramic tiles, and more and more exterior walls are gradually painted with colorful paints. Spray robots at this stage are also used steel wire sling for high-altitude spraying work, but the wire has its own weight, not easy to stretch and other shortcomings. In this paper, GFRP tendons instead of steel tendons were studied and analyzed. The mechanical properties of GFRP tendons were tested and it was found that GFRP tendons could be used instead of steel bars. Not only can save the use of steel, reduce costs, but also to a large extent, play excellent performance of glass fiber composites.
\end{abstract}

\section{Introduction}

Exterior coating of high-rise buildings is a large amount of work involved. So far, the domestic basically still stuck in the artificial spraying stage, the construction process requires workers to take the basket hanging dangerous aerial work.[1] This spraying method will bring serious safety hazard to the construction workers. Long-term direct contact will adversely affect the health of workers. At this stage of the spraying robot using steel wire suspension to achieve high-altitude spraying work, the better realization of the spray automation. However, due to the rope is not easy to stretch, its own shortcomings such as weight, resulting in spraying robot slow, difficult to operate, low efficiency and many other shortcomings.[2] Therefore, in order to make the painting robots work more conveniently and with higher efficiency, it is imminent to study a new type of material instead of the steel cord.

Based on GFRP tendons with light weight, high strength, good corrosion resistance, anti-magnetic, small proportion of advantages in many aspects of steel properties, and easy to cut and remove features. GFRP tendons instead of steel tendons are widely used in civil engineering. [3] Therefore, the use of GFRP tendons in engineering instead of the traditional common rebar, can fundamentally solve the problem caused by corrosion of steel works. This article after measuring the content of GFRP tendons and density. Through the tensile test, the apparent characteristics of the tendons of GFRP tendons with the change of tensile force were observed and the tensile strength, modulus of elasticity and Poisson's ratio of GFRP tendons were determined. Proved the advantages of glass fiber reinforced plastic instead of steel reinforcement, reached the relevant conclusions.

\section{Brief introduction of GFRP tendons}

GFRP tendons are glass fiber reinforced plastic commonly known by the public. They are a new type of material made of fiberglass and polymer matrix, accounting for a considerable proportion of polymer-based composites. [4] Most GFRP tendons have a glass fiber diameter of about 30 microns. The smaller the diameter of the glass fibers in a GFRP tendon, the better the overall performance will be. Glass fiber raw materials are mostly silicon dioxide $\left(\mathrm{SiO}_{2}\right)$, and in which calcium, boron, 
sodium, and other metal or non-metallic oxides made.

In general, the GFRP tendons have the advantages of better design, lightweight, high strength, good corrosion resistance, good fatigue performance, low conductivity and low cost. [5]

On the other hand, the weight of steel than the same volume of GFRP reinforced composite materials such as the weight of about 4 times, so the use of GFRP reinforced composite materials instead of steel can reduce the transportation and installation costs to a certain extent, but also for the high-rise building construction process of spraying robot provides a convenient.

Traditional sling material selection is steel, steel applications and research is also very mature, so in the introduction of GFRP tendons should be compared with the commonly used steel. The physical and mechanical parameters of GFRP tendons and steels are shown in Table 1.

Table 1 GFRP tendons and reinforced mechanical properties comparison

\begin{tabular}{c|c|c}
\hline Project & GFRP Tendons & Ordinary Steel \\
\hline Tensile strength $(\mathrm{MPa})$ & $500-800$ & $420-630$ \\
\hline Yield Strength $(\mathrm{MPa})$ & $/$ & $300-500$ \\
\hline Compressive strength $(\mathrm{MPa})$ & $300-400$ & $420-630$ \\
\hline Shear strength $(\mathrm{MPa})$ & 120 & $420-630$ \\
\hline Elastic Modulus $(\mathrm{GPa})$ & 40 & 200 \\
\hline $\begin{array}{c}\text { Longitudinal thermal } \\
\text { expansion coefficient }\left(10-6 /{ }^{\circ} \mathrm{C}\right)\end{array}$ & $6.0-10.0$ & 11.7 \\
\hline $\begin{array}{c}\text { Transverse thermal expansion } \\
\text { coefficient }\left(10-6 /{ }^{\circ} \mathrm{C}\right)\end{array}$ & 23 &
\end{tabular}

Note: The general bar referred to in the table is HPB300 HRBF500

From the comparison in Table 1, it can be concluded that GFRP tendons have high tensile strength, which can meet the tensile force needed in the process of spraying robots, so it can meet the safety load in the construction process. It can also be seen from Table 1 that the shear strength of GFRP tendons is much lower than the shear strength of steel bars, so GFRP tendons can be broken relatively easily by using common tools in the process of demolition. Therefore, GFRP tendons instead of reinforcing bars can meet the requirements, which can not only solve some shortcomings in the use of reinforced slings, but also give some excellent characteristics of GFRP materials to be well exerted.

\section{Tensile Mechanical Properties of GFRP Bars}

GFRP tendon content determination. Tensile test is used ribbed GFRP tendons, tendons diameter of $12 \sim 28 \mathrm{~mm}$. The resin content and glass fiber content of GFRP bars were tested according to the loss on ignition method in "Test Method for Glass Fiber Reinforced Plastics Resin Content" (GB / T 2577-2005).[6] GFRP tendons will be completely burned to obtain residual glass fiber, as shown in Figure 1, the $\varphi 12$ GFRP bar density measured by the hanging method is the maximum of the GFRP bar density of all diameters, about $2.2 \mathrm{~g} / \mathrm{cm}^{3}$. As the diameter of GFRP tendons increases, the density of tendons decreases slightly, and the minimum value of the density of $\varphi 25$ GFRP tendons is about $2.0 \mathrm{~g} / \mathrm{cm}^{3}$ for all diameters of GFRP tendons. The density of glass fiber measured by liquid displacement method is about $2.7 \mathrm{~g} / \mathrm{cm}^{3}$.[8] If we do not consider the effect of impurity and other factors on the result, we can get the content of glass fiber and matrix in GFRP bars, as shown in Table 2. 


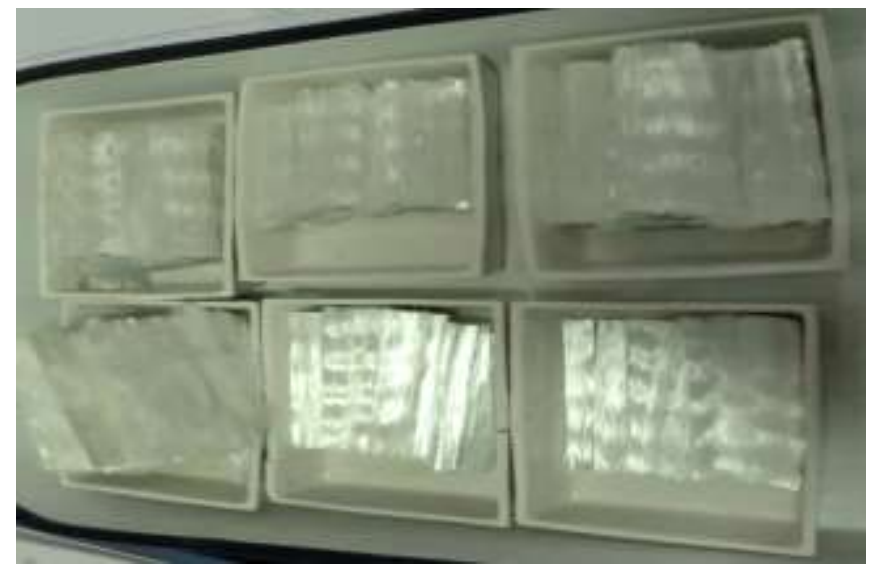

Figure 1. GFRP tendons after burning glass fibers

Table 2 GFRP tendon series corresponding to the volume ratio (\%)

\begin{tabular}{cccc}
\hline $\begin{array}{c}\text { Diameter } \\
\text { model }\end{array}$ & $\begin{array}{c}\text { Resin mass } \\
\text { content }\end{array}$ & $\begin{array}{c}\text { Fiber quality } \\
\text { content }\end{array}$ & Fiber volume ratio \\
\hline$\varphi 12$ & 14.6 & 85.3 & 71.9 \\
$\varphi 16$ & 13.0 & 87.0 & 68.6 \\
$\varphi 20$ & 15.2 & 84.8 & 65.6 \\
$\varphi 22$ & 15.8 & 84.2 & 65.7 \\
$\varphi 25$ & 16.7 & 83.3 & 63.7 \\
$\varphi 28$ & 16.5 & 83.5 & 64.6 \\
\hline
\end{tabular}

GFRP tendons tensile test apparent characteristics. The tensile strength of 6 kinds of GFRP bars with diameters of $12-28 \mathrm{~cm}$ was measured. The bars showed different bearing capacity and stress state characteristics during the tensile test.[7] Table 3 lists the tensile strength of GFRP bars of different diameters.

Table 3 GFRP tendons series diameter tensile strength

\begin{tabular}{cccc}
\hline Diameter & Type & Initial cracking load & Destroy the load \\
\hline$\varphi 12$ & & 398.1 & 526.4 \\
$\varphi 16$ & 286.1 & 547.4 \\
$\varphi 20$ & & 488.9 & 622.6 \\
$\varphi 22$ & vinyl & 376.4 & 560.6 \\
$\varphi 25$ & & 354.6 & 601.3 \\
$\varphi 28$ & & 292.5 & 571.9 \\
\hline
\end{tabular}

Tensile tests on $\varphi 28$ GFRP tendons were observed. When the tensile load reached $180 \mathrm{KN}$, the GFRP tendons began to emit a fine cleavage sound.[9] Through the crack observer, the tiny cracks along the axis of the bar body can be clearly observed in the range of $1 / 4$ of the sleeve near both ends of the bar. The measured crack width is about $0.10 \mathrm{~mm}$. As the tensile load increases, cleavage sound clearer. Figure 2 shows the location and shape of the crack on the surface of the tendon when the tendon just starts to emit the cleavage sound. As the drawing load continues to increase, the cracks become more pronounced. When the tensile load reaches $250 \mathrm{KN}$, the cleavage noise disappears [10]. At this moment, the cracks on the surface of the tendons gradually close with the decrease of tensile load. 


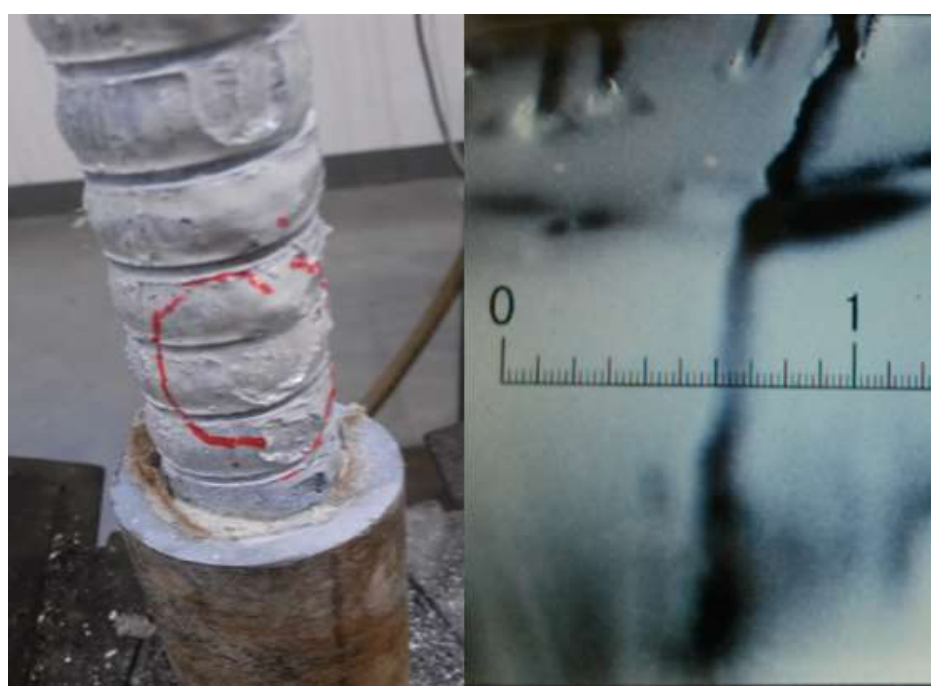

Figure 2. tendon surface cracks location, width and shape

Tensile tests were conducted on GFRP bars of other series of diameters with cleavage sounding and accompanying cracks.[11]The emergence and development of cracks are similar to the GFRP bars described above, while the GFRP bars of different series of diameters have different splitting sound and cracks at different time points, and the sizes of the stripping on the surface of the bars are also not uniform. The maximum value is $20.6 \mathrm{~mm}$, the minimum is $5.7 \mathrm{~mm}$. The maximum thickness is $5.2 \mathrm{~mm}$. The minimum is $1.8 \mathrm{~mm}$. The width of the crack distribution is between $0.1 \sim 0.4 \mathrm{~mm}$.

GFRP tendons tensile stress strain relationship. Testing the stress and strain of GFRP tendons can measure the modulus of elasticity of the tendons under tension. In the 1/2, 1/4 area of the ribs, the strain gauges along the stretching direction and in the vertical stretching direction are affixed. The total stress and strain of the GFRP tendons in two perpendicular directions are measured during the stretching process [12]. The stress-strain curve was plotted and the data were processed and analyzed with GFRP bars of $25 \mathrm{~mm}$ in diameter. Figure 3 shows the longitudinal and transverse stress-strain curves of the $1 / 2$ and $1 / 4$ zones during the GFRP webbing process.

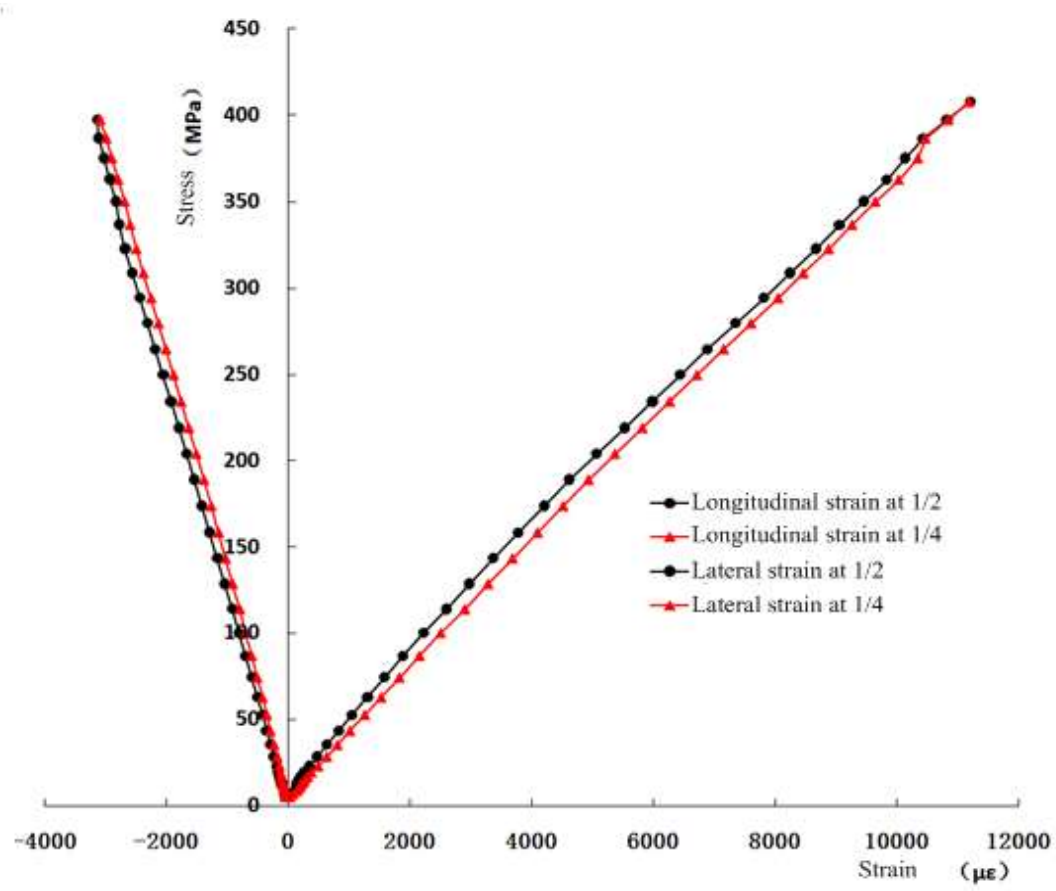

Figure 3. GFRP tendons $\varphi 25$ tensile stress-strain curve

It can be seen from Figure 3 that the strain of GFRP tendon increases linearly with the increase 
of stress, and the stress-strain curves of the 1/2 and 1/4 zones are not much different. Tensile test data obtained by calculation, the average modulus of longitudinal elasticity of $40 \sim 45 \mathrm{GPa}$, Poisson's ratio of $0.28 \sim 0.30$.

\section{Conclusions}

In this paper, through the tensile mechanical properties of GFRP tendons, the excellent properties of GFRP tendons have been proved. The use of GFRP tendons instead of steel bars as a force-bearing material for robotic robots not only saves steel bars, reduces costs, but also gives full play to the special properties of the composite. If high-rise building spray robots use GFRP bars instead of steel bars, this will greatly increase work efficiency and thus promote the rapid development of the construction industry.

\section{References}

[1]H. Peng, X. Li, J. Liu, T.X. Wang, F. Yang and Y.L, Wang: Mechanical Engineer, (2014) No.10, p.96.

[2] Q.P. Jin and L.L. Xiao: Engineering Plastics Application, Vol. 42 (2014) No.07, p.82.

[3] M.P. Hao: Fiber Glass, (2015) No.4, p.7.

[4]F. Qu, Y. Zhang, S. Ning, X.G. Guan and D.S. Yang: Machinery, Vol. 53 (2015) No.605, p.33.

[5]C.H. Wang and D. Chen: CHINA WATER TRANSPORT, Vol. 8 (2008) No.05, p.205.

[6] H. Ma, M.Z. Hou, Q.H. Guo and Y.T. Wang: Journal of He Bei Institute of Architecture and Civil Engineering, Vol. 33 (2015) No.3, p.81.

[7] Q.P. Jin, Z. Chen and X.Q. Li: China Plastics Industry, Vol. 42 (2014) No.10, p.50.

[8]F.C. Wang, L.P. Wang, X.C. Liang, J.S. Zhao and Y.J. Chou: China Science \& Technology Panorama Magazine, (2014) No.07, p.106.

[9] J.Q. Yu, X.K. Lei and J.F. Chao: Automation Panorama, (2016) No.08, p.68.

[10]F. Yuan and H. Yin: Urbanism and Architecture, (2017) No13, p.23.

[11] Q.P. Jin, W. Lu and Z. Chen: China Plastics, Vol. 28 (2014) No.11, p.67.

[12] W. Tian: The World of Building Materials, Vol. 36 (2015) No.01, p.25. 